\title{
The Impact of Free Information Technology (IT) on Financial Markets
}

\author{
Hossein Niavand \\ Research Scholar, Department of studies in Business Administration (BIMS), University \\ of Mysore, India \\ E-mail: niavandd@gmail.com
}

Farzaneh Haghighat Nia

Research Scholar, Department of studies in Commerce, University of Mysore, India

E-mail: f.haghighat67@gmail.com

\begin{abstract}
R. Mahesh
Chairman and Associate Professor, Department of studies in Business Administration (BIMS), University of Mysore, India
\end{abstract}

Received: February 10, 2018

Accepted: February 28, 2018 Published: May 9, 2018

doi:10.5296/bms.v9i1.13113

URL: https://doi.org/10.5296/bms.v9i1.13113

\begin{abstract}
This paper underlines included esteem creation through the offering of free merchandise by the online approach of the genuine worldwide financial condition. Till now, relatively every great or administration offered "for nothing" was the aftereffect of what financial experts consider to be a cross-endowment: you get a free well on the off chance that you'll purchase another great or you'll get a free item in the event that you'll pay for an administration. In the most recent decade, another free model showed up. The new model is construct not with respect to cross-sponsorships the development of cost starting with one item then onto the next however on utilizing the cost of the item as the last beginning stage. This indistinct place where there is free was the Internet. About, Thirty years back the huge online analysis was conceived; the most recent questions were the fight between free frameworks versus the paid
\end{abstract}


ones. In 2013, "The New York Times" turn out to be free, the same with "The Wall Street Journal", what was left to pay would have educational specialty esteem and a high business included esteem. The paper shapes another lead: "The 1\% Rule", this will be wrangled amid this examination through the working situations approach on the development of the connection amongst buyers and financial operators.

Keywords: Information Technology, cross-sponsorships, Moore's law, online globalization, relative cost, Free financial matters 


\section{Introduction}

\subsection{Future Approach}

In the most recent decade, another model of tip showed up. The new model is constructed not with respect to cross-endowments moving the cost from an item to another yet on utilizing the item cost as the last beginning stage. It is realized that the cost of steel diminished to almost zero and that Gillette could offer for nothing the cutting edges and even the razor, and the way that it can profit from something unique.

This unusual place that is known for nothing is the Internet. The Internet is the channel that deleted limits; limits of products and enterprises showcase that now make the worldwide economy and the worldwide dissemination of welfare through globalization. 30 years back the considerable online investigation was conceived; today the last obscure is the fight between free frameworks versus paid ones.

On account of Gillette, the possibility that you can profit by offering something free wasn't so radical. As of recently, any great or administration offered "for nothing" was the aftereffect of what market analysts considered as a cross-endowment: you get a free well in the event that you purchase another great or you'll get a free well in the event that you pay for an administration.

Once considered an advertising trap, free turned into a remain solitary monetary model. Offering free music turned out to be a win for a few groups routed to specialties and raised the quantity of groups that made pages on Myspace, fabricating high gatherings of people from zero. The part with the greatest development from the gaming business was the internet gaming industry and day by day web-based diversions managed through promotions frameworks (FarmVille, CityVille, Mafia Wars, Café World, and Zynga Poker) and free MMO (Massively Multiplayer Online) amusements. For all intents and purposes, everything that Google makes is allowed to the customer, from Gmail to Picasa.

The ascent of "free economics" is driven by subs-layer Internet advancements. Like Gordon Moore's law which manages the way that one power handling unit parts at regular intervals, yet the cost of transfer speed and capacity feels substantially quicker. What influences us to support the pattern what underlines the cost of online business has just a single end: tends to zero.

The innovation isn't free in any way, particularly when you purchase mass, yet in the event that we imagine this thing from the opposite end of the line, the monetary framework changes. That whole of hard drives (the settled cost) can serve a large number of clients (the peripheral cost). The Internet is scaled, finding better approaches for drawing in many clients to focal assets, partitioning the expenses between the immense group of onlookers and the innovation which turns out to be increasingly complex. It isn't about the cost of the important hardware for the server farm of a major online organization; it is about what that gear can do. Furthermore, consistently, similar to a Swiss watch, the hardware accomplishes an 
ever-increasing number of operations for less and less cash, driving the negligible cost of innovation per people to close to zero.

The same as when we whine about how costly are the products in nowadays. we are encompassed by powers that make them less expensive. For instance, 50 years back, the primary issue of America was the craving; today is weight, for which we need to thank the Green Revolution. 50 years prior, the philanthropy was comprehended through garments gifts to poor people. Presently you can purchase a shirt at a little cost than some espresso in the focal point of the city, because of China and worldwide outsourcing, a similar circumstance remains for toys, contraptions and some other products. Thusly cocaine has never been less expensive like today (globalization works in puzzling ways).

Advanced innovation profits by this progression and from something all the more capable: the going from the Newtonian model to the quantum display. We are still at the start of nuclear scale investigating of materials semiconductors (preparing power), ferromagnetic mixes (stockpiling units) and fiber optics (data transmission). In an authentic way, all the three ways took after are still new and we have much to gain from these. We are a couple of decades from finding another world.

What these thoughts about "free" actuate? All things considered, let us take an illustration. Dropbox was established in 2007, reported that a free administration, will offer boundless storage room. Give it a chance to be clear, "boundless" signifies "interminable". Along these lines, online capacity cost, at any rate for email, went to zero and the stunning thing is that nobody was astonished; many thought about this thing typical.

For all around established reasons: it's unmistakable now that anything which enters in contact with Internet-based advancements is winding up free, at any rate from the shopper's viewpoint. After storage room transfer speed (YouTube: free) and preparing power (Google: free) took after the race for touching the lower furthest reaches of cost. The customary economy manages that in a focused market, costs advance to the minimal cost. There has never been a more focused market like the Internet and, consistently, the peripheral cost of computerized data tends to zero.

One of the particular jokes for the finish of the 90's was that there are two numbers on the Internet: unending and zero. The first, it is for the pattern for the estimation of organizations stocks, turned out to be false. Be that as it may, the second one it is as yet substantial. The Internet turned into the place where there are free merchandise and ventures.

The outcome is that now we don't have one, however, two spread patterns with the expectation of complimentary plans of action in the economy. The first is an expansion of cross-endowments of Gillette that is connected to an ever-increasing number of ventures. Innovation gives organizations tremendous adaptability in the best way to characterize markets, allowing them more opportunity and offer free items or administrations for a buyers gathering while for another gathering offers it at a cost. Ryanair, for instance, partitioned the business through its rethinking into a full benefit tourism office as opposed to utilizing 
conventional plane ticket salespersons.

The second pattern is that anything that enters a computerized advertise enters under the quickened bringing down costs impact.

There is just the same old thing new in the deflationary power of innovation, yet what is new is the speed with which ventures wind up plainly advanced organizations and along these lines prepared to do adequately abusing the upper hand. At the point when Google changed promoting in a product application, a great administration business in light of human financial aspects (merchandise are winding up increasingly costly while years pass) has changed in programming financial matters (the merchandise are getting to be plainly less expensive).

From the purchaser's perspective, there is a major contrast amongst modest and free. On the off chance that you offer an item with the expectation of complimentary it can end up noticeably popular. Request one penny for it and you are in another business, one in which you are fighting for each customer. The "FREE" brain science is effective.

The contrast amongst shabby and free it's called "the cash hole". Individuals trust that the request is flexible and that volume enters a straight slant when the cost increments, however truly zero is a market and some other cost speaks to an alternate market. This is the contrast between a decent market and no market. The immense mental hole between "just about zero" and "zero" it is the thing that made miniaturized scale pays to fall flat. It is the reality why Google doesn't subscribe to our Visas. It is the reality why online organizations don't charge clients. Also, it's the reality for which Yahoo! offers boundless storage room. The inquiry for unending storage room isn't that "if" yet "when". The champs are the ones who give this great or administration for nothing.

Most monetary models based on free great or administration depends on the outside framework. There is an outsider who pays to take an interest in a market made through free trade between two gatherings. Sounds convoluted? It is going at the present moment, for instance, we have correspondence media.

In the customary model, a marketing specialist gives an item for nothing (or free) to shoppers and promoters pay to take an interest at showcase entrance (first books/DVDs from another accumulation are for nothing). Radio is "allowed to air" and the same with TV. The same with magazines and daily paper distributers, they don't charge the genuine cost for creation, printing, and circulation of their items. They don't pitch daily papers to peruses, they pitch peruses to publicists. It is an outsider framework showcase.

As it were, the Internet speaks to an augmentation of the business media model to modern branches. It isn't a straightforward thought that publicists will pay for everything. There are numerous routes through which media organizations can profit from free substance, from pitching data about purchasers to permitting a brand, including esteem memberships, and direct web-based business. As of now numerous online organizations are based on the 
skeleton of these models.

\section{Offer "free economy"}

Between new routes for organizations to sponsor items and bringing down business costs in the computerized period, the chance to embrace any sort of free plans of action weren't such a significant number of. The economy with a zero cost has numerous specialties for characterizing the possibility of a free offer, yet this in this exploration paper will be exhibited the ones that affect the worldwide market. The most critical specialties can be isolated into three classes:

\subsection{Cross - Subsidies}

At the point when a retailer requests 14 Euro (the normal cost in Eastern Europe) for the most recent motion picture discharged on DVD, it is a pioneer that is losing. The organization offers the DVD under expenses to pull in the customer into his store, where it plans to offer him an electronic gadget or a machine to make its genuine benefit. Costly wines sponsor modest sustenance in an eatery and the first motto "free dinner" (emergency menu) depended on a free supper offered to any individual who requested no less than one lager in a cantina in San Francisco in the of late 1800. In any items or administrations bundle, from keeping the money to added alternatives to cell phone membership designs, the cost for every individual part is resolved through mental levers, not through cost.

Cell phone organizations don't influence the benefit from the included minutes in the membership to design or in the additional alternative they keep up that low arrangement since they realize that is the main thing that the shopper sees when he picks his administrator yet the month to month anticipate information activity is the unadulterated benefit.

\subsection{Free Premium}

It can take many shapes: from allowed to selective or premium, the "ace" form, a site or programming with a larger number of choices than the free form. Be that as it may, isn't this the "free example offer" model from a perfumery or from street pharmacists? Truly, yet here it has another comprehension. Since this free specimen have genuine costs, makers give just a little amount planning to snare the shopper and to animate his interest for additional.

Yet, for computerized items, the free versus paid proportion is switched. A conventional site utilizes "The $1 \%$ Rule" - $1 \%$ of the clients manage the others.

In the freemium display, that implies that each client who pays for the professional form of the site will offer to 99 clients the fundamental form for nothing. The guideline on which this model works is that that $99 \%$ have an upkeep cost of very nearly zero.

\section{The Gift Economy}

Selflessness dependably existed, yet the Internet offers the stage through which activities of people may have overall effect. Somehow, dissemination at a cost equivalent to zero changed 
into an industry of putting in like manner. In cash based economy everything has all the earmarks of being free in fact, in the cash based economy there appears not to be a straight rivalry but rather this informs all the more regarding the tight vision of the measuring courses for esteem more than about the esteem that was made.

Released by the supernatural occurrence of plenitude, the advanced economy turned the customary economy by 180 degrees.

The whole area is based on concentrate the monetary trades and how they are made. Milton Friedman supported all the time that "there is no such thing as a free dinner"

In any case, Friedman wasn't right in two cases. Right off the bat, a free supper doesn't really imply that sustenance is offered for nothing before it spoiled or that it will be paid later it is conceivable to be selected in another person's record.

The second case, in the wild computerized, arrive, as watched, the primary trump of data economy capacity, handling force, and transmission capacity wound up plainly less expensive, with every day that passes. Two principal elements of shortage in the conventional economy the peripheral expenses of generation and circulation are in freefall. It resembles the eatery would not need to pay for its crude materials and for the work costs for setting up the feast.

It has. The word is "externality" or "outsourcing", an idea that underlines cash isn't the main irregularity during this season of worldwide emergency. Before the components presented to a shortage, there are two factors that are underlined: accessible time and regard, factors that as of late we prevailing to quantify through "consideration economy" and "notoriety economy".

There is a restricted offer of notoriety and consideration on the planet at a given minute. These are the new shortages and the universe of products and enterprises exists to buy these important resources for the benefit of the plan of action.

\section{Conclusion}

Today computerized innovation is hip since it turned out to be too shoddy to possibly be measured and in light of the fact that it can eradicate limits, even those limits are unmistakable (physical limits) or elusive (social or instructive limits). It took us decades to escape from the biased suspicion that handling power was intended to the few and just now we can free the data transfer capacity and capacity from creative energy's neediness.

By improving the availability of free internet in various communities, we will improve the marketing of companies to increase sales. Governments take away by providing inexpensive Internet infrastructure for the people a big step in creating jobs and marketing.

Between computerized economy and crossed offering grasped by Gillette's analysis in light of value development, we enter a period where the "zero cost" will turn into a run, not an oddity.

Be that as it may, an age raised on the free Internet structure emerges to the development and 
it will discover better approaches to grasp squander, changing the world amid the procedure. Since free is the thing that it is needed, what I need and what we need and more data will be accessible for nothing. Be that as it may, there is a circumstance that wasn't taken in thought: in the start of the third thousand years, we had the dot.com bubble, one of the little emergencies that cumulated into the genuine worldwide monetary emergency which is by all accounts interminable. The real worldwide financial condition can stand another emergency even on a little scale, so the quickened economy from the IT\&C business must be delicately controlled to make a proactive administration way to deal with a conceivable future anomaly: the dot.com bubble 2.0, in view of the over-assessment of Internet based organizations, similar to Twitter, Facebook, LinkedIn or other online administration makers and integrators. Those organizations taken as remain solitary are not perilous for the worldwide economy, but rather their IPO's and the system economy impact will make an additional weight on the worldwide monetary advancement and its manageable sending.

\section{Acknowledgements}

The authors are grateful to the Publisher and the anonymous referees for helpful comments and suggestions. We are the gratitude of all professors of BIMS (University of Mysore) for their highly constructive comments and guidance. We also thank the Student Affairs and Scientific and Educational Advisor council of the Islamic Republic of Iran in India and subcontinent, Professor Seyed Mohammad Reza Khalili, for the sake of financial and scientific support. Hossein Niavand is grateful to the University Grand Commission (UGC) of India for financial support through a grant. The usual disclaimer applies, and views are the sole responsibility of the authors.

\section{References}

Anderson, C. (2008). Free! Why $\$ 0.00$ is the future of business. Wired Magazine, 16(3), 16-03. Retrieved from http://www.wired.com/print/techbiz/it/magazine/16-03/ff_free.

Bhide, A. (1994). How entrepreneurs craft strategies that work. Harvard Business Review, 72(2), 150-161.

Bodislav, D. A. (2011). The Eco-Innovational Approach for the Energy of the Future. Quality Access to Success, (121), 358-363.

Friedman, M. (1971). A monetary theory of nominal income. Journal of Political Economy, 79(2), 323-337. https://doi.org/10.1086/259746

Nevens, T. M. (1990). Commercializing technology: what the best companies do. Planning Review, 18(6), 20-24. https://doi.org/10.1108/eb054310

Pascu, B., Ratezanu, I., \& Stan, I. L. (2016). Creating Sustainable and Safe Green Energy. Calitatea, 17(S1), 408.

Rock, A. (1987). Strategy vs tactics from a venture capitalist. Harvard Business Review, 65(6), 63-67. Retrieved from https://hbr.org/1987/11/strategy-vs-tactics-from-a-venture-capitalist 


\section{Copyright}

Copyright for this article is retained by the author(s), with first publication rights granted to the journal.

This is an open-access article distributed under the terms and conditions of the Creative Commons Attribution license (http://creativecommons.org/licenses/by/4.0/). 